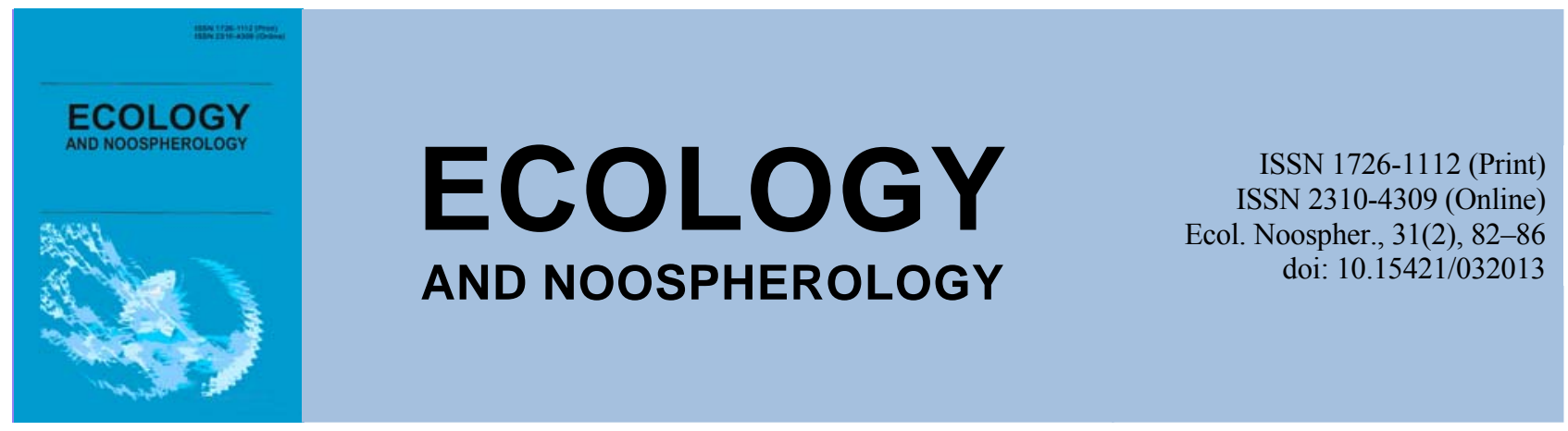

\title{
Features of soil thermophysical properties of the southern variant of ravine biogeocenoses of the Ukrainian steppe zone
}

\author{
V. A. Gorban \\ Oles Honchar Dnipro National University, Dnipro, Ukraine
}

Article info

Received 08.10.2020

Received in revised form

17.10.2020

Accepted 25.10.2020

Oles Honchar Dnipro

National University,

Gagarin Ave., 72, Dnipro,

49010, Ukraine.

Tel.: +38-050-362-45-90

E-mail:vad01@ua.fm
Gorban. V. A. (2020). Features of soil thermophysical properties of the southern variant of ravine biogeocenoses of the Ukrainian steppe zone. Ecology and Noospherology, 31(2), 82-86. doi:10.15421/032013

Thermophysical properties are an important characteristic of the general condition of soils, which determine the peculiarities of the distribution of heat flow in them. Today studies of thermophysical properties of soils, including the steppe zone of Ukraine, are practically not performed. This determines the relevance of the work, which is devoted to establishing the characteristics of the thermal properties of various soils. As a result of the study of thermal diffusivity, heat capacity and thermal conductivity of soils of northern and southern exposures, as well as the thalweg of the Voyskovoy Bayrak (located near the village of Voyskovoe Solonyansky district of Dnipropetrovsk region), it was found that the most important soil factors particles of physical clay and organic matter content. It was found that the eluvial horizons of the chernozem of the forest of the northern exposure differ in the reduced values of heat capacity and thermal conductivity in comparison with the illuvial horizons. Eluvial horizons of forest-meadow soil of thalweg are characterized by increased values of thermal diffusivity and thermal conductivity, as well as reduced values of heat capacity compared to illuvial horizons. Eluvial horizons of forest chernozem of southern exposure are characterized by lower values of thermal diffusivity, heat capacity and thermal conductivity compared to illuvial horizons. The most significant boundary between eluvial and illuvial horizons in terms of thermophysical properties is characteristic of the chernozem of forest southern exposure, which is manifested in a sharp increase in the values of thermophysical properties in the first illuvial horizon. Cluster analysis revealed that the most similar in terms of thermal diffusivity are forest chernozems of southern and northern exposures, and in terms of heat capacity and thermal conductivity - forest chernozems of northern exposure and forest-meadow soil of thalweg ravine.

Keywords: forest chernozem; forest-meadow soil; thermal diffusivity; heat capacity; thermal conductivity; content of physical clay particles; content of organic matter

\section{Особливості теплофізичних властивостей грунтів південного варіанта байрачних біогеоценозів степової зони України}

\author{
В. А. Горбань
}

\section{Дніпровський національний університет імені Олеся Гончара, Дніпро, Україна}

Теплофізичні властивості є важливою характеристикою загального стану грунтів, що визначають особливості розподілу в них теплового потоку. На сьогодні дослідження теплофізичних властивостей грунтів, в тому числі степової зони України, практично не виконуються. Це зумовлює актуальність проведення робіт, які присвячені встановленню особливостей теплових властивостей різноманітних грунтів. У результаті дослідження температуропровідності, теплоємності та теплопровідності грунтів північної та південної експозицій, а також тальвегу байраку Військового (розташованого поблизу c. Військового Солонянського р-ну Дніпропетровської обл.) установлено, що найголовнішими грунтовими факторами, які визначають теплофізичні властивості досліджуваних грунтів, є вміст часток фізичної глини та вміст органічної речовини. Виявлено, що елювіальні горизонти чорнозему лісового північної експозиції відрізняються зменшеними значеннями теплоємності та теплопровідності порівняно 3 ілювіальними горизонтами. Елювіальні горизонти лісово-лучного грунту 
тальвегу характеризуються збільшеними значеннями температуропровідності та теплопровідності, а також зменшеними значеннями теплоємності порівняно з ілювіальними горизонтами. Елювіальним горизонтам чорнозему лісового південної експозиції притаманні менші значення температуропровідності, теплоємності та теплопровідності порівняно з ілювіальними горизонтами. Найбільш значуща межа між елювіальними та ілювіальними горизонтами за значеннями теплофізичних властивостей характерна для чорнозему лісового південної експозиції, яка проявляється у стрибкоподібному збільшенні величин теплофізичних властивостей у першому ілювіальному горизонті. Кластерний аналіз виявив, що за значеннями температуропровідності найбільш подібними є чорноземи лісові південної та північної експозицій, а за величинами теплоємності та теплопровідності - чорнозем лісовий північної експозиції та лісово-лучний грунт тальвегу байраку.

Ключові слова: чорнозем лісовий; лісово-лучний грунт; температуропровідність; теплоємність; теплопровідність; уміст часток фізичної глини; уміст органічної речовини

\section{Вступ}

Теплофізичні властивості грунту $\epsilon$ його важливою характеристикою, яка визначає накопичення та рух тепла в грунті, а також впливає на температуру та тепловий потік у грунті залежно від часу та глибини (Abu-Hamdeh, 2003). Розподіл теплового потоку в грунті визначається його трьома основними тепловими властивостями: теплопровідністю $(\lambda), \quad$ теплоємністю $\quad(\mathrm{C}) \quad$ та температуропровідністю $(\alpha=\lambda / \mathrm{C})$ (Оуеуеті et al., 2018). Зміни температури впливають на комплекс фізичних властивостей грунту, що призводить до зміни ії теплових властивостей (Boukelia et al., 2019).

Дослідження, виконані Abu-Hamdeh та Reeder (2000), свідчать, що теплопровідність збільшується зі збільшенням щільності грунту та вмістом вологи. Зростання вмісту доданих солей та процентного вмісту органічної речовини в грунті зменшує теплопровідність. У цілому піщані грунти відрізняються більшими значеннями теплопровідності порівняно з глинистим суглинком (Abu-Hamdeh, Reeder, 2000). Результати досліджень Vidana Gamage et al. (2019) свідчать, що теплофізичні властивості грунту більше залежать від умісту в ньому вологи, ніж від умісту органічної речовини та структурно-агрегатного складу. Інші вчені наводять дані, що теплофізичні властивості грунту визначаються переважно загальним умістом органічної речовини, а не структурно-агрегатним складом, щільністю та вологістю (Zhu et al., 2019). Результати, отримані $\mathrm{Xu}$ et al. (2020), свідчать, що збільшення щільності грунту призводить до зменшення теплопровідності і майже не впливає на теплоємність. До основних факторів, які визначають теплові властивості грунту, Usowicz et al. (2017) відносять уміст кварцу та води, а також щільність грунту.

Наведені дані свідчать, що теплофізичні властивості грунту $\epsilon$ його комплексною характеристикою, яка для кожного окремого грунту залежить від специфічного ряду грунтових умов (умісту вологості, органічної речовини та солей, гранулометричного та структурно-агрегатного складу, щільності та ін.).

Крім того, вчені наводять дані про існування певних залежностей між теплофізичними властивостями грунту, зокрема теплопровідності, та потоками парникових газів, які виділяються або поглинаються грунтом (Vakanda Nkongolo et al., 2010).

Виходячи $з$ цього, особливої актуальності набувають дослідження теплофізичних властивостей грунтів зі збільшеним умістом органічної речовини, якими є грунти природних байрачних лісів степової зони України.

Мета роботи - дослідження особливостей теплофізичних властивостей грунтів природних байрачних лісів південного варіанта степової зони України.

\section{Матеріали та методи досліджень}

Дослідження теплофізичних властивостей грунтів байрачних біогеоценозів південного варіанта степової зони України виконували 3 використанням грунтових зразків, відібраних 3 трьох грунтових розрізів, закладених на середніх третинах північної та південної експозицій, а також у тальвегу байраку Військового (с. Військове Солонянського р-ну Дніпропетровської обл.).

Детальний опис пробних площ та макроморфологічної характеристики грунтових профілів наведено в нашій попередній роботі (Gorban et al., 2020). Нижче наводимо стислі дані.

Пробна площа № 1 розташована в середній третині схилу $3^{\circ}$ північної експозиції. Тип лісового біогеоценозу природна свіжа пакленова діброва з дубовим широкотрав'ям (Dn2). Грунтовий профіль: H1el (0-10 см) + H2el (10-30 см) + H3el $(30-50$ см) + Hil (50-100 см) + Phil (100-150 см $)+$ P $\left(\begin{array}{ll}150-170 & \mathrm{~cm}\end{array}\right)$. Назва грунту - лісовий чорнозем сильновилугований середньолесивований середньогумусовий на делювіальних відкладах.

Пробна площа № 2 розташована на дні тальвегу. Глибина грунтових вод - 1,0 м. Тип лісового біогеоценозу природний вологий осичняк (BC3). Грунтовий профіль: H1el $(0-10$ см) + H2el (10-40 см) + H3el (40-70 см) + Hil (70-100 см). Назва грунту - лучно-лісовий чорноземоподібний сильновилугований середньогумусовий на делювіальних відкладах.

Пробна площа № 3 розташована в середній третині схилу $16^{\circ}$ південної експозиції. Тип лісового біогеоценозу природна сухувата чорнокленова діброва 3 фіалкою шершавою (Е1). Грунтовий профіль: H1el $(0-10 \mathrm{~cm})+\mathrm{H} 2 \mathrm{el}$ $(10-34 \mathrm{~cm})+\mathrm{H} 3 \mathrm{el}(34-54 \mathrm{~cm})+\mathrm{Hil}(54-92 \mathrm{~cm})+$ Phkil $(92-120$ см) + Pk (120-150 см). Назва грунту - чорнозем лісовий вилугований середньолесивований середньогумусовий на лесових відкладах.

Визначення теплофізичних властивостей грунту (температуропровідність, теплоємність та теплопровідність) виконували методом імпульсного нагрівання, який найбільш часто використовується при таких дослідженнях (AbuHamdeh, Reeder, 2000; Bachmann et al., 2001). Дослідження виконували 3 використанням установки та програмного забезпечення, наведеного в нашій роботі (Gorban V., Gorban A., 2007).

Усі вимірювання виконувались триразово. Отримані результати піддавалися статистичній обробці (розрахунок середніх значень, стандартної похибки, кластерний аналіз), яка виконувалася за допомогою програм Microsoft Excel та Statistica.

\section{Результати та їх обговорення}

Дослідження теплофізичних властивостей чорнозему лісового північної експозиції байраку пробної площі 1 (табл. 1) виявили, що збільшеними значеннями температуропровідності відрізняються горизонти $\mathrm{H} 1 \mathrm{el}$ та $\mathrm{P}$ $\left(6,226\right.$ та $6,396 \times 10^{-7} \mathrm{~m}^{2} / \mathrm{c}$ відповідно). При цьому збільшене значення температуропровідності горизонту H1el можна пояснити збільшеним умістом органічної речовини $i$, як наслідок, iї високою абсорбційною здатністю, збільшеним умістом гігроскопічної вологи (Vidana Gamage et al., 2019). Збільшене значення температуропровідності горизонту P зумовлене його підвищеною щільністю та збільшеним умістом часток фізичної глини внаслідок їх вимивання 3 верхніх горизонтів в результаті лесиважу (Travleyev et al., 2007). Верхні елювіальні горизонти H1el, H2el та H3el характеризуються зменшеними значеннями теплоємності 
Таблиця 1

Теплофізичні властивості чорнозему лісового північної експозиції байраку Військового (пробна площа 1)

\begin{tabular}{ccccc}
\hline $\begin{array}{c}\text { Генетичний } \\
\text { горизонт }\end{array}$ & $\begin{array}{c}\text { Глибина, } \\
\text { см }\end{array}$ & $\begin{array}{c}\text { Температуропровідність, } 10^{-7} \\
\mathrm{~m}^{2} / \mathrm{c}\end{array}$ & $\begin{array}{c}\text { Теплоємність, } \\
\left.\text { МДж/(м }{ }^{3} \cdot \mathrm{K}\right)\end{array}$ & $\begin{array}{c}\text { Теплопровідність, } \\
\text { Дж/(м*c·К) }\end{array}$ \\
\hline H1el & $0-10$ & $6,226 \pm 0,430$ & $1,230 \pm 0,048$ & $0,767 \pm 0,076$ \\
H2el & $10-30$ & $6,181 \pm 0,641$ & $1,217 \pm 0,050$ & $0,754 \pm 0,103$ \\
H3el & $30-50$ & $6,068 \pm 0,392$ & $1,258 \pm 0,045$ & $0,764 \pm 0,072$ \\
Hil & $50-100$ & $6,117 \pm 0,672$ & $1,270 \pm 0,036$ & $0,778 \pm 0,107$ \\
Phil & $100-150$ & $6,176 \pm 0,365$ & $1,249 \pm 0,026$ & $0,772 \pm 0,060$ \\
P & $150-170$ & $6,396 \pm 0,329$ & $1,255 \pm 0,038$ & $0,803 \pm 0,061$ \\
\hline
\end{tabular}

$\left(1,230,1,217\right.$ та 1,258 МДж/( $\left.\mathrm{m}^{3} \cdot \mathrm{K}\right)$ відповідно) порівняно 3 ілювіальними горизонтами. Максимальне значення

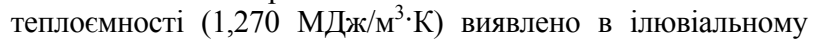
горизонті Hil, який межує з елювіальними горизонтами, i характеризується збагаченням частками фізичної глини, вимитими з верхніх горизонтів. Елювіальні горизонти H1el, $\mathrm{H} 2 \mathrm{el}$ та H3el також відрізняються зменшеними величинами теплопровідності $\quad(0,767, \quad 0,754$ та 0,764 Дж/(м'с·K) відповідно) порівняно 3 ілювіальними горизонтами. Максимальне значення теплопровідності виявлено в горизонті $\mathrm{P}(0,803$ Дж/(м'c·K)).

Аналіз теплофізичних властивостей лісово-лучного грунту тальвегу байраку пробної площі 2 (табл. 2) встановив, що верхні елювіальні горизонти H1el, H2el та $\mathrm{H} 3 \mathrm{el}$ відрізняються збільшеними величинами температуропровідності $\left(6,382,6,382\right.$ та $6,232 \times 10^{-7} \mathrm{~m}^{2} / \mathrm{c}$ відповідно) порівняно з ілювіальним горизонтом Нil. Таке поступове зменшення величин температуропровідності 3 глибиною зумовлене особливостями розподілу органічної речовини в даному грунті (Zhu et al., 2019), максимальний уміст якої припадає на верхні горизонти, а 3 глибиною спостерігається зменшення її вмісту (Travleyev et al., 2005). Збільшені значення теплоємності характерні для горизонтів H2el та Hil (1,247 та 1,244 МДж/( $\left.{ }^{3} \cdot \mathrm{K}\right)$ відповідно). У цілому даний грунт відрізняється достатньо вузьким інтервалом величин теплоємності всіх досліджуваних горизонтів, що може свідчити про значний уміст у них органічної речовини. Верхнім елювіальним горизонтам H1el, H2el та H3el також властиві збільшені значення теплопровідності $(0,772,0,796$ та 0,763 Дж/(м·c·К) відповідно) порівняно з ілювіальним горизонтом Hil. Це може бути зумовлено розташуванням у верхніх горизонтах переважної більшості коренів деревної та трав'яної рослинності, уміст яких у грунті призводить до збільшення його теплопровідності (Fu et al., 2020).
Результати дослідження теплофізичних властивостей чорнозему лісового південної експозиції байраку пробної площі 3 (табл. 3) виявили, що серед верхніх елювіальних горизонтів збільшеним значенням температуропровідності відрізняється горизонт H2el $\left(6,168 \times 10^{-7} \mathrm{~m}^{2} / \mathrm{c}\right)$. Ілювіальні горизонти Hil та Phkil відрізняються збільшеними величинами температуропровідності порівняно 3 елювіальними горизонтами, що свідчить про значний вплив на величину температуропровідності вмісту часток фізичної глини (Abu-Hamdeh, Reeder, 2000). Верхні елювіальні горизонти H1el, H2el та H3el також відрізняються зменшеними величинами теплоємності $\left(1,147,1,141\right.$ та 1,143 МДж/( $\left.\mathrm{m}^{3} \cdot \mathrm{K}\right)$ відповідно) порівняно 3 ілювіальними горизонтами. Це свідчить про відсутність впливу вмісту органічної речовини на значення цієї теплофізичної характеристики. Так само верхні елювіальні горизонти $\mathrm{H} 1 \mathrm{el}$, $\mathrm{H} 2 \mathrm{el}$ та $\mathrm{H} 3 \mathrm{el}$ характеризуються зменшеними значеннями теплопровідності $(0,668,0,703$ та 0,643 Дж/(м'c·K) відповідно) порівняно 3 ілювіальними горизонтами. Кластерний аналіз отриманих результатів виявив, що за величинами температуропровідності серед трьох досліджуваних грунтів більш подібними $є$ чорноземи лісові північної та південної експозицій байраку пробних площ 1 та 3 , які разом утворюють одну групу (рис. 1).

Кластерний аналіз величин теплоємності всіх досліджуваних грунтів показав подібність за цією характеристикою чорнозему лісового північної експозиції байраку пробної площі 1 та лісово-лучного грунту тальвегу байраку пробної площі 2 , які разом утворюють одну групу (рис. 2).

Подібними до результатів кластерного аналізу величин теплоємності виявилися результати кластерного аналізу величин теплопровідності (рис. 3). Установлено формування однієї групи чорноземом лісовим північної експозиції байраку пробної площі 1 та лісово-лучним грунтом тальвегу байраку пробної площі 2.

Таблиця 2

Теплофізичні властивості лісово-лучного грунту тальвегу байраку Військового (пробна площа 2)

\begin{tabular}{|c|c|c|c|c|}
\hline $\begin{array}{l}\text { Генетичний } \\
\text { горизонт }\end{array}$ & $\begin{array}{c}\text { Глибина, } \\
\text { см }\end{array}$ & $\begin{array}{c}\text { Температуропровідність, } 10^{-7} \\
\mathrm{~m}^{2} / \mathrm{c}\end{array}$ & $\begin{array}{l}\text { Теплоємність, } \\
\left.\text { МДж/( } \mathrm{M}^{3} \cdot \mathrm{K}\right)\end{array}$ & $\begin{array}{c}\text { Теплопровідність, } \\
\text { Дж/(м•c·К) }\end{array}$ \\
\hline H1el & $0-10$ & $6,382 \pm 0,437$ & $1,210 \pm 0,010$ & $0,772 \pm 0,050$ \\
\hline $\mathrm{H} 2 \mathrm{el}$ & $10-40$ & $6,382 \pm 0,339$ & $1,247 \pm 0,012$ & $0,796 \pm 0,050$ \\
\hline $\mathrm{H} 3 \mathrm{el}$ & $40-70$ & $6,232 \pm 0,393$ & $1,222 \pm 0,064$ & $0,763 \pm 0,088$ \\
\hline Hil & $70-100$ & $5,684 \pm 0,212$ & $1,244 \pm 0,019$ & $0,707 \pm 0,037$ \\
\hline
\end{tabular}

Таблиця 3

Теплофізичні властивості чорнозему лісового південної експозиції байраку Військового (пробна площа 3)

\begin{tabular}{|c|c|c|c|c|}
\hline $\begin{array}{l}\text { Генетичний } \\
\text { горизонт }\end{array}$ & $\begin{array}{c}\text { Глибина, } \\
\text { см }\end{array}$ & $\begin{array}{c}\text { Температуропровідність, } 10^{-7} \\
\mathrm{~m}^{2} / \mathrm{c}\end{array}$ & $\begin{array}{l}\text { Теплоємність, } \\
\left.\text { МДж/( } \mathrm{M}^{3} \cdot \mathrm{K}\right)\end{array}$ & $\begin{array}{c}\text { Теплопровідність, } \\
\text { Дж/(м'с·К) }\end{array}$ \\
\hline H1el & $0-10$ & $5,809 \pm 0,956$ & $1,147 \pm 0,049$ & $0,668 \pm 0,129$ \\
\hline $\mathrm{H} 2 \mathrm{el}$ & $10-34$ & $6,168 \pm 0,286$ & $1,141 \pm 0,079$ & $0,703 \pm 0,053$ \\
\hline $\mathrm{H} 3 \mathrm{el}$ & $34-54$ & $5,617 \pm 0,211$ & $1,143 \pm 0,098$ & $0,643 \pm 0,072$ \\
\hline Hil & $54-92$ & $6,005 \pm 0,368$ & $1,190 \pm 0,067$ & $0,716 \pm 0,085$ \\
\hline Phkil & $92-120$ & $6,505 \pm 0,771$ & $1,132 \pm 0,100$ & $0,737 \pm 0,110$ \\
\hline $\mathrm{Pk}$ & $120-150$ & $5,835 \pm 0,640$ & $1,177 \pm 0,072$ & $0,688 \pm 0,103$ \\
\hline
\end{tabular}




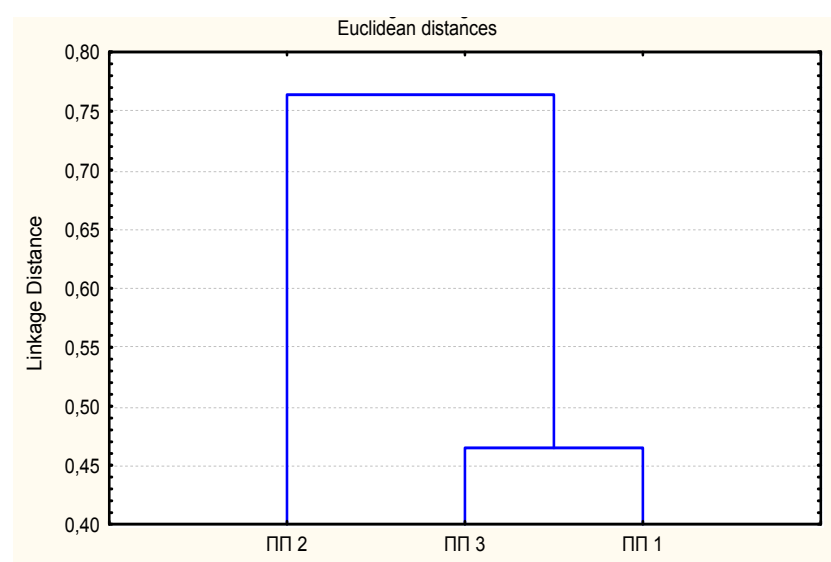

Рис. 1. Кластерний аналіз значень температуропровідності досліджуваних грунтів

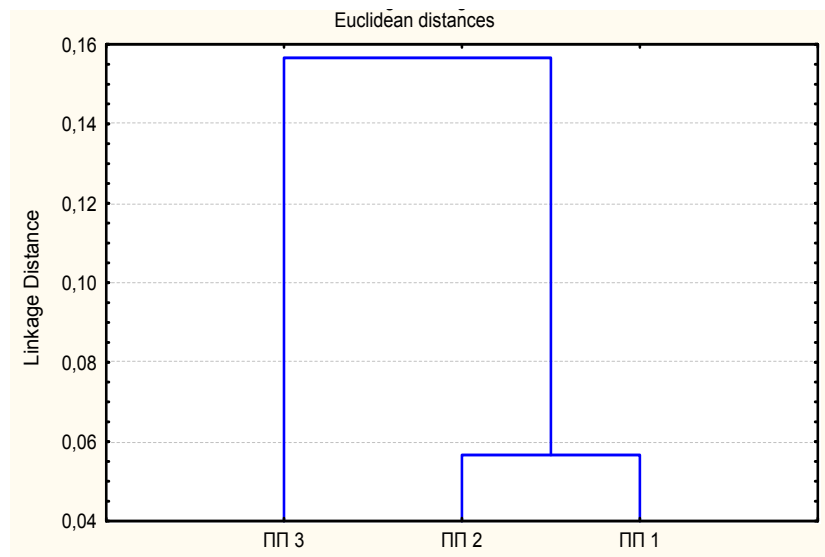

Рис. 2. Кластерний аналіз значень теплоємності досліджуваних грунтів

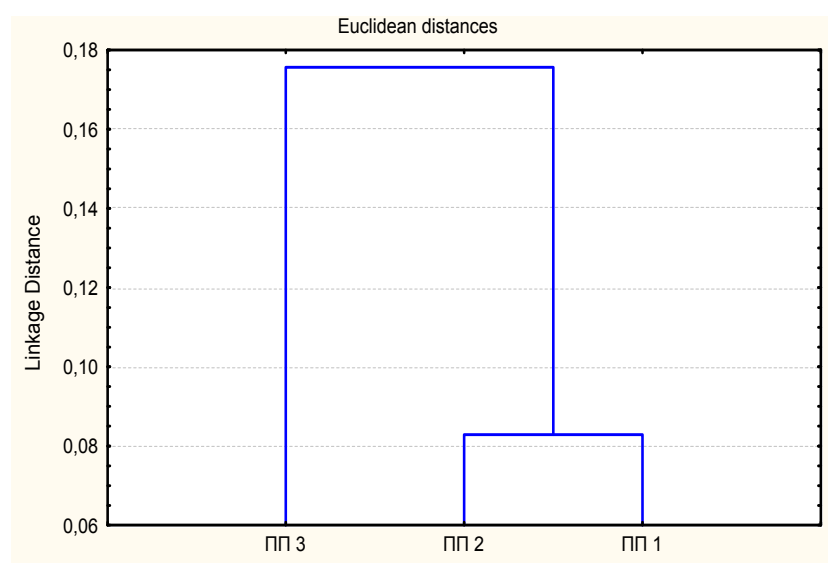

Рис. 3. Кластерний аналіз значень теплопровідності досліджуваних грунтів

Таким чином, за значеннями температуропровідності більш подібними $є$ чорноземи лісові південної та північної експозицій, а за величинами теплоємності та теплопровідності - чорнозем лісовий північної експозиції та лісово-лучний грунт тальвегу байраку.

\section{Висновки}

1. Найбільше на величини теплофізичних властивостей грунтів байраку Військового впливають уміст часток фізичної глини, а також уміст органічної речовини.

2. Елювіальні горизонти чорнозему лісового північної експозиції відрізняються зменшеними значеннями теплоємності та теплопровідності порівняно 3 ілювіальними горизонтами.

3. Елювіальні горизонти лісово-лучного грунту тальвегу характеризуються збільшеними значеннями температуропровідності та теплопровідності, а також зменшеними значеннями теплоємності порівняно 3 ілювіальними горизонтами.

4. Елювіальним горизонтам чорнозему лісового південної експозиції притаманні менші значення температуропровідності, теплоємності та теплопровідності порівняно з ілювіальними горизонтами.

5. Найбільш значуща межа між елювіальними та ілювіальними горизонтами за значеннями теплофізичних властивостей характерна для чорнозему лісового південної експозиції, яка проявляється у стрибкоподібному збільшенні величин теплофізичних властивостей у першому ілювіальному горизонті.

6. Кластерний аналіз виявив, що за значеннями температуропровідності найбільш подібними $є$ чорноземи лісові південної та північної експозицій, а за величинами теплоємності та теплопровідності - чорнозем лісовий північної експозиції та лісово-лучний грунт тальвегу байраку. 


\section{References}

Abu-Hamdeh, N. H. (2003). Thermal properties of soils as affected by density and water content. Biosystems Engineering, 86(1), 97-102.

Abu-Hamdeh, N. H., Reeder, R. C. (2000). Soil thermal conductivity: Effects of density, moisture, salt concentration, and organic matter. Soil Science Society of America Journal, 64(4), 1285-1290.

Bachmann, J., Horton, R., Ren, T., Van Der Ploeg, R. R. (2001). Comparison of the thermal properties of four wettable and four water-repellent soils. Soil Science Society of America Journal, 65(6), 1675-1679.

Boukelia, A., Eslami, H., Rosin-Paumier, S., Masrouri, F. (2019). Effect of temperature and initial state on variation of thermal parameters of fine compacted soils. European Journal of Environmental and Civil Engineering, 23 (9), 1125-1138.

Fu, Y., Lu, Y., Heitman, J., Ren, T. (2020). Root-induced changes in soil thermal and dielectric properties should not be ignored. Geoderma, 370, 114352.

Gorban, V. A., Gorban, A. A. (2007). Issledovanie teplofizicheskikh svoistv pochvy metodom impulsnogo nagreva [Investigation of the thermalphysic soil properties with the help of an impulse heating method]. Gruntoznavstvo, 8(3-4), 95-99 (in Russian).

Gorban, V. A., Kuptsova, K. S., Ostrianyn, N. S., Tetiukha, O. G. (2020). Osoblyvosti strukturno-ahrehatnoho skladu edafotopiv bayrachnykh lisiv pivdennoho varianta stepovoyi zony Ukrayiny [Structural and aggregate composition features of southern variant natural forest edaphotopes of Ukrainian steppe zone]. Ecology and Noospherology, 31(1), 16-22.

Oyeyemi, K. D., Sanuade, O. A., Oladunjoye, M. A., Aizebeokhai, A. P., Olaojo, A. A., Fatoba, J. O., Olofinnade, O. M., Ayara, W. A., Oladapo, O. (2018). Data on the thermal properties of soil and its moisture content. Data in Brief, 17, 900-906.

Travleyev, A. P., Bilova, N. A., Bogovin, A. V., Dubina, A. O. (2005). Bajrachnye lesa byvshej porozhystoj chasti Dnepra sostavnaya chast ekologicheskoj seti yuga Ukrainy [Valley forests of the previous Dnipro river rapids - as component of south Ukraine ecological net]. Ecology and noospherology, 16, 3-4, 75-94 (in Russian).

Travleyev, A. P., Recio Espejo, J. M., Belova, N. A., Kuuznetzov, J. V., Balalajev, A. K., Kuuznetzov, V. J. Mikromorfologiya lessivazhnykh protsessov v bayrachnykh lesnykh chernozemakh stepnoy zony Ukrainy [Micromorpholodgy of the intersoil processes typical for ravine forests' chernozem of the Ukrainian steppe zone]. Gruntoznavstvo, 8, 1-2, 6-24 (in Russian).

Usowicz, B., Łukowski, M. I., Rüdiger, C., Walker, J. P., Marczewski, W. (2017). Thermal properties of soil in the Murrumbidgee River Catchment (Australia). International Journal of Heat and Mass Transfer, 115, B, 604-614.

Vakanda Nkongolo, N., Johnson, S., Schmidt, K., Eivazi, F. (2010). Greenhouse gases fluxes and soil thermal properties in a pasture in central Missouri. Journal of Environmental Sciences, 22, 7, 1029-1039.

Vidana Gamage, D. N., Biswas, A., Strachan, I. B. (2019). Spatial variability of soil thermal properties and their relationships with physical properties at field scale. Soil and Tillage Research, 193, 50-58.

Xu, Y., Zeng, Z., Sun, D., Lv, H. (2020). Comparative study on thermal properties of undisturbed and compacted lateritic soils subjected to drying and wetting. Engineering Geology, 277, 105800.

Zhu, D., Ciais, P., Krinner, G., Maignan, F., Jornet Puig, A., Hugelius, G. (2019). Controls of soil organic matter on soil thermal dynamics in the northern high latitudes. Nature Communications, 10 (1), № 3172. 